Portland State University

PDXScholar

1979

\title{
The Effect of Administrative Mandate on Social Workers' Clinical Decision Making
}

Richard Arthur Anderson

Portland State University

Follow this and additional works at: https://pdxscholar.library.pdx.edu/open_access_etds

Part of the Business Administration, Management, and Operations Commons, and the Social Work Commons

Let us know how access to this document benefits you.

\section{Recommended Citation}

Anderson, Richard Arthur, "The Effect of Administrative Mandate on Social Workers' Clinical Decision Making" (1979). Dissertations and Theses. Paper 2759.

https://doi.org/10.15760/etd.2742

This Thesis is brought to you for free and open access. It has been accepted for inclusion in Dissertations and Theses by an authorized administrator of PDXScholar. Please contact us if we can make this document more accessible: pdxscholar@pdx.edu. 
THE EFFECT OF ADMINISTRATIVE MANDATE ON

SOCIAL WORKERS' CLINICAL DECISION MAKING

by

Richard Arthur Anderson

A practicum submitted in partial fulfillment of the requirements for the degree of

MASTER OF SOCIAL WORK

Portland State University

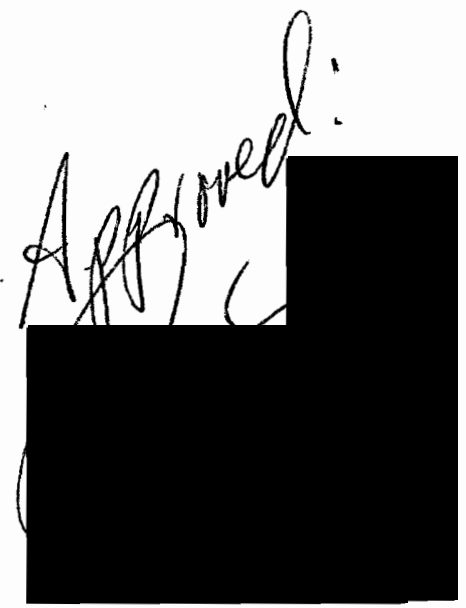




\section{ACKNOWLEDGEMENTS}

The author wishes to recognize the following three individuals who contributed their time, expertise and organizational abilities toward collecting the data which was essential to this study.

Jerome Casey, MSW Chief, Social Work Service

Portland Veterans Administration

Medical Center

Cecil Munson, MSW Chief, Social Work Service

Togus Veterans Administration

Regional Office and Medical Center

George Rajewsk1, MSW Chief, Social Work Service

Vancouver Veterans Administration

Medical Center 
TABLE OF CONTENTS

PAGE

ACKNOWLEDGEMENTS. . . . . . . . . . . . . . . . . . . . $1 i$ LIST OF TABLES. . . . . . . . . . . . . . . . . . . . iv CHAPTER

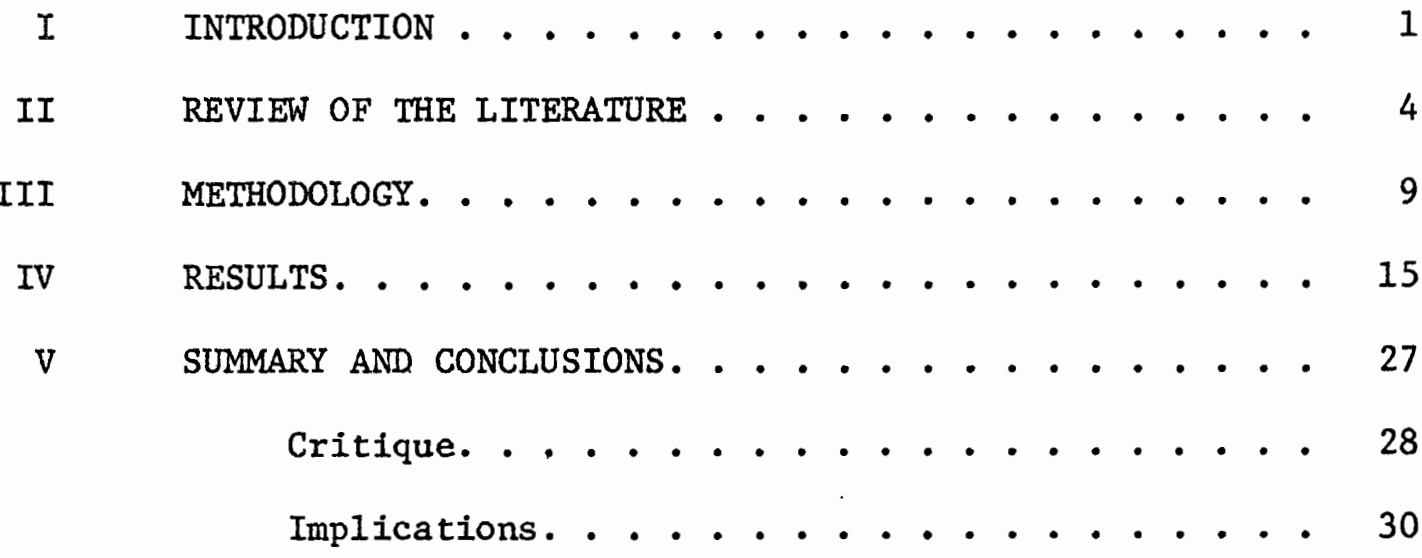

BIBLIOGRAPHY. . . . . . . . . . . . . . . . . . 32

APPENDIX. . . . . . . . . . . . . . . . . . 35 


\section{LIST OF TABLES}

TABLE

PAGE

I A Comparison of the Number of Patients Discharged or Retained in Each of Ten Cases, and the Degree of

Certainty Expressed by the Subjects in Their Choices . . . . . . . . . . . . 15

II A Comparison of the Number of Patients Discharged or Retained Presented by Case Number and Group. . . 17

III A Summarization of the Mean Certainty Experienced

by Subjects for Each of Five Case Decisions . . . 18

IV A Comparison Between Groups of Sex, Age, and Work

Experience Variables. . . . . . . . . . 18

V A Comparison of Supervisory Personnel Responses to

Decision to Retain or Discharge Patients

Expressed as Percent. . . . . . . . . . . . . 19

VI A Comparison of the Monthly Bed Turnover Rates for

Three Veterans Administration Hospitals

Expressed as Percent. . . . . . . . . . 20

VII A Comparison of the Discharge Rate of Three Matched

Paírs From Group B. . . . . . . . . . . . 24 
CHAPTER I

INTRODUCTION

The purpose of this study is to explore the extent to which Social Workers' clinical judgement is altered by administrative needs in a population of Veterans Administration social workers.

In the course of duty; hospital social workers are often called upon to make clinical decisions. These decisions may be made autonomously or they may be made as a participating member of a "team" or in conjunction with other professionals. In any case, these decisions affect the treatment and outcome of the clients' situation and ultimately their welfare. One might wonder how much of these clinical decisions are based purely on clinical factors and by contrast, how much of the decisions are based on other non-clinical factors.

The importance and significance of this study is related to the client's need to be treated for his problems when he enters a given institution rather than being treated according to the problems and needs of the institution. For the professional social worker, it is important to be free to use his clinical judgement in behalf of his client without irrelevant constraints. Further, the perception of the social worker by the client should be free of the suspicion that the worker is serving as a minion of the bureaucracy rather than as a professional. 
The importance of this study to research is to find out whether administrative mandates do, in fact, influence social workers' clinical judgement, hence altering treatment to some significant degree.

Administrators will be interested in seeing whether there is acceptance or resistance to their directives and what factors are involved in this dimension.

Ideally, one might regard the notion of a professional's clinical judgement as sacred and thus incorruptible. In practice, there are numerous intervening reality factors which might influence the outcome of a given clinical decision. A few of these non-clinical variables are: priority of the service needed by the patient, availability of hospital beds or alternative community services, funds available for extended treatment, trends in health care, public opinion, political pressure, and administrative needs which might prove crucial to future budgetary considerations.

This researcher has been in the position to observe numerous types of administrative policy or decision changes which have had the potential of affecting clinical judgement in regard to the population served. For example, within some Veterans Administration Hospitals there have been administrative directives to either reduce or increase the number of outpatient cases served in a given program or to reduce or increase the ratio of service-connected to non-service connected cases served. There have also been directives aimed at reducing the number of beds in a given hospital or on a particular ward. The nationwide policy change of treating the mentally 111 in the community rather than keeping these clients indefinitely as institutional wards 
undoubtedly had some effect on professionals' judgement as to the patients' suitability for discharge.

These types of administrative directives may be translated operationally to the ward social worker as, "take another look through the ward to see whether there aren't some patients we can move on to nursing homes or personal care homes." For the outpatient social worker the directive may take the form of, "go through your case load and get rid of the dead wood."

So, one may ask, do some of our clients simply become figures to be manipulated and shifted from one program or excluded from another in order to satisfy administrative needs? More directly, to what extent can our clinical judgement as professional social workers be corrupted by non-clinical variables?

The settings for this study included three V.A. hospitals located respectively in Togus, Maine; Portland, Oregon; and Vancouver, Washington. One basic assumption in using these particular hospitals is that the professional social work staff is recruited according to similar Federal standards for the social work positions thus providing continuity in their academic backgrounds. They are subjected to similar chains of command and central office directives and must make the same kinds of decisions from hospital to hospital in their dally practice.

The hypothesis of this study is that given the same clinical material and clinical decision to be made, professional social workers' decisions will be significantly influenced by an added administrative directive. 


\section{LITERATURE REVIEW}

In reviewing the literature, the author found a paucity of experte mental work either specifically or generally pertinent to the subject? of factors influencing social workers' clinical judgement. Two compqtep searches were Initiatzed through the National Library of Medicipge, National Interactive Retrleval Servłce (Medlars II). The off-Itne bibḷlographic citation 11sts generated by these searches numbered nine and eleven respectively.

Given the deanth of research pelevant to this study, this rexter of the literature w111 consider qnity a spall numben of references and wili raise some questions which are thelated to this experiment but will not necessarily be answered by this experiment,

In social work, professionals are increasingly held responstbit for their practice by their peers, the organization in which they woxk, and the public. Accountability has shifted from the admiṇistrative levels, the director and supervisory personnel, to the practitfoners. The growth of utllization review committees, hospltal audit comittens, peer review commlttees, and quality assurance programs has Inviolved all lévels of professionals in the setting up of standards, criterla, programs, and the mọnttoring of services (Hirsch and Schulman, 1976, p. 433). Given this shift to the practitioners in accountabilify, the traditional organizatfonal model in hospltal departments of 
social work which has been authoritarian in structure, no longer seems appropriate. Rather, the new model proposes a partnership between the administrators and the practitioners.

One underlying assumption which becomes basic to this partnership is that the individual social worker is a self-governing, responsible person whose professional objectives are consonant with both the goals of the department and the overall goals of the institution.

The governance component of administration is that parameter limited to the decision-making processes that determine or affect policies, procedures, and the direction in which goals, programs, and services will evolve. Another way of looking at governance is as a process of keeping the institution's and the department's goals in viable balance (Hirsch and Schulman; 1976, p 434), thus, considering the operational needs and imperatives such as ward coverage, patient discharge, community services, teaching and research. Decision making, then, becomes a way in which the balance may be maintained and the department is made productive and effective.

In a participatory governance there are flexible roles and decision making is not by mandate from above but rather from explicit participation of departmental staff. Some of the literature further supports the notion that particlpation in governance is healthy in that it can improve morale, productivity, and the quality of output (Lawrence and Sinith, 1955; Hungate, 1964).

In a large institution, to what degree are the individual social work practitioners isolated from the policy decisions which may affect thetr practice? There is a psychological and emotional distance as 
we11 as the more obvious power and control divisions which separate the staff from the administration. How do these factors influence decision making at the individual level? When policy decisions are mandated from above, to what extent does the social work practitioner attend to that mandate in relation to his own view of reality which is increasingly giving him, rather than the administration, primary responsibility for his own decisions?

One might ask whether it is realistic to speak of shared responsibility in governance of social work departments within institutions that are vertical monoliths. According to Hirsch and Schulman (1976) hospitals tend to be organized in a feudal model with a king (director) who mediates among strong barons (service or department heads) and governs through a bargaining, negotiating process. Decisions may be made for the good of the institution, the good of the population it serves, or in deference to the power of the particular barons. Depending upon whether the social worker views administrative decisions as administrative needs or patients' needs, he may choose to either discount or reinforce those mandates which are handed down.

What are some of the non-medical variables which influence the effectiveness of hospital treatment? According to Krell (1977), if information on patient characteristics and social factors, such as age, sex, marital status, living arrangements, financial resources, and family ties were obtained systematically, discharge planning and continuity of care could be conducted more meaningfully. While the Joint Commission on the Accreditation of Hospitals (JCAH) in 1972 made social work services a mandatory requirement for hospitals, 
there are still no uniform standards for staffing or minimum service requirements. If the social worker then is to be a critical component in the discharge process, uniform staffing standards should be developed. In a survey of Boston city hospitals, Barber (1973) reported that $63 \%$ of hospital overstay was related to problems of a psychosocial nature.

There is a degree of mystery and hence mistrust between the roles of administrator and clinician. Does this affect the translation of goals to operational directives and thence to individual staff actions? This question will not be addressed specifically in this study but it is closely related to the topic. In examining the psychiatristadministrator's relationship with his medical peers and to his relationships with other administrative professionals within the community, Beigel (1975) suggests that he often encounters conflicts and misunderstandings which contribute to difficulties in carrying out his tasks. Others in the community view the psychiatrist who enters into the administrative role as being out of his area of expertise and in an area of no concern to him. Motivations and opinions regarding administrative matters will be questioned and possibly rejected because he is a psychiatrist and not expected to understand administrative issues.

On the other hand, the psychiatrist-administrator may be rejected by his own peers as having "gone over to the other side." There is a strong inclincation and temptation for the psychiatrist-administrator to avoid continuing personal clinical involvement because of the burdens of administrative responsibility. This choice leads to 
"administrative sterility" ( $\left.0^{\mathrm{N}} \mathrm{Neil1}, 1970\right)$ and further compounds the relationship with medical peers. Similarly, social work practitioners may well experience conflict and misunderstanding in carrying out their tasks while at the same time trying to integrate the directives of professional administrators and social work administrators.

One area, then, that the experimenter will be looking at will be the degree of conflict experienced by the subjects used in this study when faced with making a clinical decision given an administrative directive. It will be important to note whether the subjects attend to the administrative need in their subjective comments and the degree of certainty they experience in making each decision. 
CHAPTER III

\section{METHODOLOGY}

The population used in this investigation consisted of forty-four professional social workers at the Masters level as a minimum. The workers all had some experience in clinical, hospital social work and a familiarity with inpatient treatment. The complete Social Work Service staffs of three separate Veterans Administration Hospitals were asked to participate in this study on a voluntary basis. All forty-four agreed to participate.

This project was carried out as a three-group experimental design with one group serving as a control. All three groups were given the same amount of information about the experiment. A11 workers who participated were blind as to the purpose of the study beyond the hope that it would increase the fund of knowledge in social work.

The social work staff of nine at Vancouver Veterans Administration Medical Center (V-VAMC) was designated as "Group A," an experimental group. The social work staff of thirteen at'Portland Veterans Administration Medical Center (P-VAMC) was designated as "Group B," the second experimental group. The twenty-two social workers of Togus Veterans Administration Medical Center (T-VAMC) were designated as "Group C," the control group. Thus, the social workers from a given 
hospital staff were not randomly assigned to different groups. Rather, all members of a given staff were placed arbitrarily in the same experimental or control group based solely on their membership in that staff.

It will be the research hypothesis of this experiment that the experimental groups will make clinical decisions which are significantly different from the control group. Furthex, it is hypothesized that the two experimental groups will be algnificantly different from each other in the clinical decisions they make. Difference between groups w11l be analyzed statistically and defined operationally as discharge rate. The discharge rate will be determined by the number of patients the social workers choose to discharge versus the number of pattents they choose to retain as inpatients. The null hypothesis will state that there is no difference in the discharge rate between the two experimental groups or between the discharge rate of ther of the experimental groups and the control group.

One example of a clinical decision social workers in hospitals must make to to dermine whether a patient should be discharged. having recelved maximum hospital benefits, or should be rotalind for further inpatlent treatment. This decision, to diacharge or to retain a patient for further treatment, served as the dapendent variable In this atudy. The Independent variable wes an administrative mandete or need which was 1ntroduced in the material presented to the subjecto. In thio study, the "administrative need" was to al ther increase or decrease the number of beds used in the hospital. 
The tecinnique used to gather data was printed questionnaires directed to professional social workers as subjects. Initially, the researcher constructed ten short case histories which basically consisted of the same categories and amounts of information. The categories included age, sex, diagnosis, length of hospitalization, previous history, current condition and attitude of the patient, financial and significant family situation. The subjects were asked to make two decisions regarding each case-first, should the patient be discharged or retained as an inpatient and second, to rate the degree of certainty of their decision based on a five point scale representing a continuum of responses from very unsure to very sure. These ten case histories served as a pretest to determine which cases were most unambiguous in regard to the decision to be made. There was no "administrative need" to be considered in the pretest. This test was given to eight Masters level social workers who had clinical experience with inpatient hospital settings but who were not currently working for the Veterans Administration. The subjects used in the pretest volunteered from the local social work agencies and were not necessarily known to the investigator.

The final questionnaire was developed from the pretest. The five case histories from the original ten which were least ambiguous in terms of subjective response were selected to be included on the final ques tionnaire.

Clear and equal instructions were printed at the beginning of each questionnaire. The subjects were asked to read the instructions carefully and fully and were admonished not to discuss their reactions or responses with anyone before all data was collected. In order to 
reduce the effect of administrative policy or directives they might have currently felt constrained by, the subjects were asked to respond to the material based on their general professional experience rather than only on the basis of their present work setting.

In group $A$, the first experimental group, the statement "it is given that the hospital administration hopes to reduce the number of beds used in this hospital" was added to each of the subject's instructions. This was the operationally defined administrative need or independent variable.

In group $B$, the second experimental group, an opposite but equal statement "it is given that the hospital administration hopes to increase the number of beds used in this hospital" was added to each of the subject's instructions. This, too, was an operationally defined administrative need.

In group $C$, the control group, no administrative need was introduced within the instructions or anywhere else. Thus, ideally, the control group responded to the case histories and made their decisions based purely on clinical and psychosocial variables.

Thus, all three groups of social workers were presented with the same five case histories and asked to make a decision to either discharge or retain the patient for further treatment. In addition, they were all asked to list their sex, age, rank in social work service, number of years of post MSW experience and finally, number of years of V.A. service in social work. These variables were deemed relevant in comparing the three groups and possibly significant in examining the responses of subgroups either across or within the design groups. 
Al1 questionnaires were presented to the individual staff members with the approval of and through the supervision of the Chief Social Worker in each of the three hospitals during January 1979. Only one worker was aware of the nature of this research study or the hypothesis; all others were blind. The one social worker with knowledge of the study immediately disqualified himself from participating as a subject and rather served to facilitate data collection.

For the purposes of this study "clinical variables" will be defined as a broad category which will include not only medical factors but also psycho-social factors such as financial resources, family support systems and patient attitude.

The experimenter sought to present the independent variable (the administrative need) in a subtle fashion so as not to bias the emphasis placed on it by the workers. Thus, the administrative need was presented in the instructions rather than repeatedly through the case material. In addition, it was actually presented as a need, rather than as a direct instruction.

Once the results of this experiment were tabulated, it became apparent that the responses were not at all what the experimenter had anticipated. It seemed that experimental group B had chosen to do the opposite of their administrative mandate. At this point the researcher decided to interview each of the subjects of that group individually to determine their perception of the independent variable. If their perception of the variable was different from that of the researcher's perception, it would give further understanding to the results of the study. 
Since the incerviewing revealed that ten of the subjects in group B perceived the independent variable in a sense opposite to the intended meaning, it was decided to further analyze the data. The other three members of group $B$ who perceived the independent variable as a need to decrease discharge rate (as intended by the experimenter) were matched according to age, rank and work experience variablés with three members of the ten of group $B$ who perceived the independent variable as a need to increase the discharge rate. A students $T$ test and a Sandler's A test were then calculated for the difference in discharge rate between these three related samples.

Further, the overall bed turnover rate was calculated for each of the three medical centers used. The rate was determined from hospital statistics of the quarter immediately preceding the experiment, October through December 1978. This calculation was computed and compared as it occurred to the researcher that the social worker's customary rate and need to discharge might be a confounding variable which had not been controlled.

Chi square tests of significant differences were computed for comparing discharge rate between groups $A$ and $B$, groups $A$ and $C$, and groups B and C. All tests were computed as two talled with the appropriate degrees of freedom. Confidence critexia for this experiment was established with $\mathrm{p} \leq .05$ as the cut off for significant results. Finally, as part of the experimental design, the researcher dectded to do an analysis of variance for any of the personal variables (sex, age, rank, and experience) which appeared to differ markedly between groups. All findings will be presented in the following chapter titled RESULTS. 


\section{CHAPTER IV}

\section{RESULTS}

The initial part of this experiment asked eight social workers to respond to a printed questionnaire describing ten case histories of hospitalized veterans. The subjects were asked to make a decision to either discharge or retain each of the patients and to indicate their degree of certainty in making the decisions on a five-point scale with five being most certain--seven subjects responded. Table I summarizes their choices and certainty from this pre test.

\section{TABLE I}

A COMPARISON OF THE NUMBER OF PATIENTS DISCHARGED OR RETAINED

IN EACH OF TEN CASES AND THE DEGREE OF CERTAINTY EXPRESSED BY THE SUBJECTS IN THEIR CHOICES

$\begin{array}{ccccc}\text { Case } & \text { Discharge } & \text { Certainty } & \text { Retain } & \text { Certainty } \\ 1 & 2 & 4.0 & 5 & 4.4 \\ 2 * & 4 & 4.0 & 3 & 4.0 \\ 3 & 2 & 4.5 & 5 & 4.6 \\ 4 * & 0 & -5.3 & 6 & 4.6 \\ 5 * & 7 & 3.4 & 0 & -- \\ 6 & 3 & 4.8 & 4 & 3.8 \\ 7 * & 6 & 4.0 & 0 & -- \\ 8 * & 1 & 4.7 & 6 & 4.4 \\ 9 & 7 & 4.7 & 0 & -- \\ 10 & 3 & 4.3 & 4 & 3.3\end{array}$


The purpose of this pretest was to choose appropriate case histories for inclusion on the final questionnaire and to receive information on the format, instructions and content of the test. Subjective responses indicated that the instructions were.clear. The case histories which were chosen for inclusion in the final questionnaire were 非, 非, 非, 非 and 非. These five cases were chosen because they best represented a continum of responses with a low degree of ambiguity and a high degree of certainty of choice as reported by the social workers tested. Case $\# 4$ and Case $\$ 8$ were clearly perceived as clients who should be retained as inpatients. while Case \#5 and \#7 were percelved as clients who should be discharged from inpatient treatment. Case 非 represented a fairly even split between discharge or retention for further treatment. The mean degree of certainty for these five cases was 4.4 out of a possible 5.0 .

The final questionnalre presented these five case histories to forty-four social workers. All forty-four subjects responded. The same questions which were asked in the pretest were repeated in the final questionnaire. The only difference was that the experimental groups ( $A$ and $B$ ) were exposed to an administrative need in addition to the case material and instructions.

Table II summarizes the responses to the question "Should the client be discharged or retained for further inpatient treatment," for each of the three groups. 
TABLE II

A COMPARISON OF THE NUMBER OF PATIENTS DISCHARGED OR RETAINED PRESENTED BY CASE NUMBER AND GROUP

Case Number

$\begin{array}{llrrrrrr}\text { Group } & & 1 & 2 & 3 & 4 & 5 & \text { Total } \\ \text { A } & \text { Discharge } & 7 & 0 & 3 & 5 & 1 & 16 \\ & \text { Retain } & 2 & 7 & 3 & 3 & 7 & 22 \\ \text { B } & \text { Discharge } & 11 & 4 & 11 & 12 & 6 & 44 \\ & \text { Retain } & 2 & 9 & 2 & 1 & 7 & 21 \\ \text { C } & \text { Discharge } & 15 & 1 & 11 & 12 & 3 & 42 \\ & \text { Retain } & 7 & 21 & 11 & 10 & 19 & 68\end{array}$

There is essentially no difference between the responses of group A, the first experimental group and group $C$, the control group. There is, however, a significant difference (Chi square $=13.08$ degrees of freedom $-1 ; p<.001$ for two tailed test) between the discharge rate of the second experimental group $B$ and the discharge rate of the control group $C$. There is also a significant difference between the discharge rates of the two experimental groups $A$ and $B$, chi square $=5.447$, degrees of freedom $=1 ; \mathrm{p}<.02$ for a two tailed test. Thus, group B discharged significantly more patients than either of the other two groups.

The second question asked of all three groups was to indicate the degree of certainty expressed in their responses. Table III lists the degree of certainty expressed by the forty-four subjects responding. 
TABLE III

A SUMMARIZATION OF THE MEAN CERTAINTY

EXPERIENCED BY SUBJECTS FOR

EACH OF FIVE CASE DECISIONS

\begin{tabular}{|c|c|c|c|c|c|c|c|}
\hline \multirow[b]{2}{*}{ Group } & \multirow[b]{2}{*}{. } & \multicolumn{5}{|c|}{ Case Number } & \multirow{2}{*}{$\begin{array}{r}\text { Total } \\
\text { Mean }\end{array}$} \\
\hline & & 1 & 2 & 3 & 4 & 5 & \\
\hline \multirow[t]{2}{*}{ A } & Discharge & 4.4 & $-\infty$ & 3.3 & 3.0 & 4.0 & 3.8 \\
\hline & Retain & 3.0 & 4.3 & 3.3 & 4.3 & 4.0 & 4.0 \\
\hline \multirow[t]{2}{*}{ B } & Discharge & 4.3 & 5.0 & 4.7 & 4.3 & 4.8 & 4.5 \\
\hline & Retain & 4.5 & 4.4 & 2.5 & 5.0 & 4.6 & 4.3 \\
\hline \multirow[t]{2}{*}{ C } & Discharge & 4.2 & 3.0 & 4.3 & 3.8 & 2.7 & 3.9 \\
\hline & Retain & 4.6 & 4.1 & 4.4 & 4.0 & 4.2 & 4.2 \\
\hline
\end{tabular}

These figures are based on a scale of 1-5 with 5 the highest degree of certainty possible and 1 the lowest. As in Table II, groups $A$ and $C$ are very close in their responses. Group B social workers show a somewhat higher degree of certainty in their decision to discharge significantly more patients. All three groups indicate high certainty in making their decisions.

The sex, age, and work experience variables for the subjects are listed by group in Table IV.

\section{TABLE IV}

A COMPARISON BETWEEN GROUPS OF SEX, AGE, AND WORK EXPERIENCE VARIABLES

\begin{tabular}{|c|c|c|c|c|c|}
\hline \multirow[b]{2}{*}{ Group } & \multicolumn{2}{|c|}{ Sex } & Mean & $\begin{array}{l}\text { Mean Years } \\
\text { of Post MSW }\end{array}$ & $\begin{array}{l}\text { Mean Years } \\
\text { of VA MSW }\end{array}$ \\
\hline & M & $\mathrm{F}$ & Age & Experience & \\
\hline A & 5 & 4 & 52.4 & 8.4 & 7.1 \\
\hline B & 6 & 7 & 40.2 & 11.7 & 7.2 \\
\hline C & 13 & 9 & 50.2 & 16.9 & 8.8 \\
\hline
\end{tabular}


An analysis of variance was calculated for the age category as this was the one variable on which the experimental groups differed markedly. In this case $F=1.688$ which was not significant. While the control group had a much higher value for "mean years of post MSW experfence" than either of the experimental groups, no conclusions were drawn from this difference.

Table $V$ lists the responses of the supervisory personnel only in each of the three groups to the question "should the patient be retained or discharged."

TABLE V

A COMPARISON OF SUPERVISORY PERSONNEL RESPONSES TO DECISION TO RETAIN OR DISCHARGE PATIENTS

(Expressed as Percent)

\begin{tabular}{|c|c|c|c|c|c|c|c|}
\hline \multirow[b]{2}{*}{ Group } & & \multicolumn{5}{|c|}{ Case } & \multirow{2}{*}{ Tota1 } \\
\hline & & 1 & 2 & 3 & 4 & 5 & \\
\hline \multirow[t]{2}{*}{ A } & Discharge & צ- & -- & 100 & 100 & -- & 2 \\
\hline & Retain & 100 & 100 & -- & -- & 100 & 3 \\
\hline \multirow[t]{2}{*}{ B } & Discharge & 100 & 33 & 100 & 67 & 33 & 10 \\
\hline & Retain & -- & 67 & -- & 33 & 67 & 5 \\
\hline \multirow[t]{2}{*}{ C } & Discharge & 100 & -- & 67 & 67 & 33 & 6 \\
\hline & Retain & -- & 100 & 33 & 33 & 67 & 7 \\
\hline
\end{tabular}

The supervisory personnel did not differ significantly from their staffs in either the direction of their decisions or the proportion of discharges to retentions they made in the experiment. Group B supervisors differed from the other two groups in the same direction and proportion, however, as the total group did in making the same decision, see Table II. 
After the experiment had been completed, the experimenter thought that bed turnover rate within the hospitals might be a variable which would influence social workers' decision to discharge clients. Table VI is a summary of the actual bed turnover rate for each hospital used in the experiment during the quarterly period immediately preceding the study.

\section{TABLE VI}

A COMPARISON OF THE MONTHLY BED TURNOVER RATE FOR THREE VETERANS ADMINISTRATION HOSPITALS (Expressed as Percent)

$\begin{array}{ccc}\text { Hospital } & \text { Group } & \begin{array}{c}\text { Turnover } \\ \text { Rate }\end{array} \\ \text { V-VAMC } & \text { A } & 130 \\ \text { P-VAMC } & \text { B } & 292 \\ \text { T-VAMC } & \text { C } & 110\end{array}$

While no Tests of Significance were run on this data, it seems relevant that Group $B^{\prime}$ 's turnover rate is $2-1 / 2$ to 3 times as great as the other groups' turnover rate. This means that these social workers are accustomed to seeing more discharges occur more quickly than the other workers. No conclusion may be drawn from this data but it would be prudent to consider this variable in future research in this area.

When this experiment was first contemplated, randomization of subject assignment to groups A, B, or C was considered as a means of further refining the results by minimizing the effect of possible differences from one hospital staff to another. Randomization was 
rejected as a technique because the researcher feared possible collaboration among staff social workers who are normally close and share a great deal of information. By keeping the groups pure as to administrative "need" it was thought that there would be less chance of any individual discovering the intent and hypothesis of the study. One of the instructions in the questionnaire was "It is imperative that you do not discuss your reactions or responses to this test with anyone else until all data has been collected..." In spite of this instruction, there was evidence that subjects shared their impressions with one another as some of the written, informal comments were strikingly similar. It appears that this behavior was kept to a minimum, however.

Having made a decision not to randomize subject assignment, several measures were instituted to minimize differences between groups. First, the chief social worker in each hospital was designated as coordinator of data collection for his own staff. They were given equal directions for distributing the questionnaires and collecting the data. Ashort time limit for completion of the questionnaires was requested to further minimize the chance of collaboration.

It was also considered possible that the individual subject's mode of responding would be influenced by his present work setting and the nature of his experience and perception of the administrative chain of command he is confronted with from day to day. Thus, each worker was asked to respond to the material "based on your general professional experience rather than...from the context of your present work setting." It was hoped that this instruction would 
minimize the blasing effect of a particularly weak or strong administrative influence from one hospital to the other.

The variables of sex, age, rank, number of years of post MSW experience, and the number of years of V.A. service in social work were recorded and deemed relevant to determining significant variance between groups and were later used for matching. There was no evidence of discernable trends based on subgroups of these categories. For example, the researcher wondered whether the supervisory personnel would attend to the administrative need more or less closely than the Iine workers. There was no significant difference found between these two groups' responses. An analysis of variance was conducted on the age differences between the two experimental groups but it was not significant.

In designing the questionnaire, the author sought to make the independent variable subtle in its presentation so as not to bias the emphasis placed on it by the workers. By placing the administrative need in the instructions, it did not have to be repeated in each case yet had the potential of influencing all that followed. Giving opposite mandates (It is given that the hospital administration hopes to either increase or decrease the number of beds in use in the hospital) to the experimental groups was by design an attempt to clearly define differences between groups. Later analysis indicated, however, that the mandates or administrative needs were not perceived as opposites by the subjects.

Clearly, an unexpected and confounding variable arose in regard to the presentation of the independent variable. "It is given that 
the hospital administration hopes to increase the number of beds used In this hospital" was translated by the researcher as a need to keep the beds filled. One way to keep beds filled is to reduce or delay discharges, thus keeping the census high. The majority of social workers in experimental group B, however, interpreted the statement differently. They perce1ved this independent variable as meaning "we need to increase the turnover rate by discharging more patients more quickly." Further confounding was the fact that this perception was not unanimous. Three workers perceived the need as the author had 1ntended it. A11 this Information was determined by the researcher's Individual Interviewing of the staff members after the original data had baen collected.

Thus, the results show a signifleant difference between the discharge rate of groups $\mathrm{B}$ and $\mathrm{C}\left(\mathrm{x}^{2} ; \mathrm{p}<.001\right)$ and a significant difference between groups $A$ and $B$ in discharge rate $\left(x^{2} ; p<.02\right)$ but it appeared to the researcher that the dfference was in the opposite direction of the given adminiotrative need. This unexpected outcome prompted postmterviowing of each of the members of Group in in regard to their perception of the independent variabia. The results of that inter. viewing make the higher discharge rate of group B undargtandable as they appear to bo responding to ned to Increase turnover race. Whyle this finding tends to support the hypotherio that soetal workers' c11nical judgement 18 gignificanty affected by admintotative needs, the reault axe clouded by the fact that three member of group perceived the Independent vartable oppostely to the ret of thetr group. In order to further clarify the resulto and oupport for the hypotheols, the data was analyod further, 
The members of group B who were perceiving a need to decrease turnover rate were matched by age, experience, and rank with members of group B who perceived a need to increase turnover rate. The results of the comparison of the responses of these three pairs are listed in Table VII.

TABLE VII

A COMPARISON OF THE DISCHARGE RATE OF THREE MATCHED PAIRS FROM GROUP B

Cases

3 subjects perceiving need to decrease turnover rate

$\begin{array}{cccccc}1 & 2 & 3 & 4 & 5 & \text { Total } \\ D R & D^{2} R & D^{2} & \text { D R } & \text { D R } & \text { D R }\end{array}$

3 subjects perceiving need to increase turnover rate

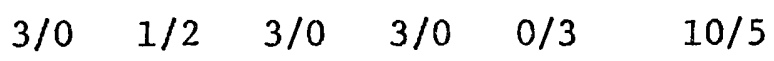

$3 / 0 \quad 3 / 0 \quad 3 / 0 \quad 3 / 0 \quad 3 / 0 \quad 15 / 0$

$\mathrm{D}=$ Discharge

$\mathrm{R}=$ Retain

These responses were analyzed statistically by student's $t$ test for matched groups and Sandler's A for correlated samples. Both tests yielded significant differences between the correlated samples $(p<.05)$ for two tailed values. This lends further support to accepting the hypothesis that social workers' clinical decisions are influenced by administrative need.

Another potentially confounding variable was discovered after. the experiment took place which was neither anticipated nor controlled for in the original design. The subjects of group B work in a "teaching hospital" where there normally seems to be much more pressure for bed turnover as indicated by the data summarized in Table VI. 
This suggests to the researcher that the group B workers, in their daily practice, might become more likely to perceive clients as ready for discharge than workers from the other two groups. Asking the subjects to respond from their overall clinical background was an attempt to control for this type of variable. The marked discrepancy In turnover rate between hospitals cannot be considered a confounding variable in the case of the significant findings of the correlated samples of group B, however, since all these subjects are from the same group.

The fact that there was no significant difference between the discharge rate of groups $A$ and $C$ does not support the hypothesis that the group A workers would be influenced by their administrative need. Given that the hospital administration wishes to decrease the number of beds in use in the hospital, the researcher again wonders how. this need was perceived and translated by the staff. It is possible that there was also ambiguity in the manner in which this need was presented and perceived. No attempt was made to further investigate the perceptions of the subjects of group $C$ as was done with group B, so it is not known whether they experienced the independent varlable as ambiguous.

The results in Tables I and IV indicate that there was a high rate of confidence in the decisions made by the social workers in both the pretest and the final test. The results also indicate that the degree of certainty was farily constant between groups in the final test. These results reinforce the notion that the case material presented was appropriate and adequate to making the necessary 
decisions. Thus, the degree of ambiguity within the presented case histories was Iow.

In the instructions on the questionnaires the subjects were invited to make written, informal, unstructured comments in regard to the matexial. It was noted by many subjects that their decisions were based on the assumption that a full range of alternatives was available to the clients if they were to return to the community. This assumption seems basic to the decision to discharge a patient but it was not clearly stated on the test. Comments in this category support the implication that social workers make decisions based not only on purely clinical, medical or psychiatric variables but also attend to the psychosocial variables.

It was curious to note that not one subject made written comment in regard to the presented independent variable. When the members of group B were interviewed after the experiment, half of them indicated that they would not normally attend to the administrative need in their practice; that it did not concern them. It remains unsettled how many subjects did actually respond to the administrative need and whether their responses were conscious or unconscious. 


\section{CHAPTER V}

\section{SUMMARY AND CONCLUSIONS}

A controlled three group, experimental design was devised to test the hypothesis that adninistrative needs significantly influence social workers' clinical judgement. Social Work Service staffs from three Veterans Administration hospitals were asked to make a clinical decision which, in this case, was to discharge or retain given patients for further treatment. An administrative need was introduced in the two experimental groups but not in the control group. Discharge rate was calculated for all three groups and used as a basis for statistical analysis.

The statistical analyses of the number of discharges made by each of the three groups revealed a significant difference in the number of discharges made by one of the experimental groups (P-VAMC) compared with both the other experimental group and the control group. The test instrument was a printed questionnaire and the response rate was 100 percent among the forty-four subjects polled.

Further analysis of the findings revealed that there was unintended ambiguity in the perception of the meaning of the independent variable. Thus, more refined statistical analyses were carried out on the results of one experimental group (P-VAMC) which examined the responses of three matched pairs of subjects. These analyses yielded significant differences which were positively correlated with the 
subjects perception of the independent variable. There was no difference between the discharge rate of the first experimental group (V-VAMC) and the control group (T-VAMC).

Based on the results obtained in this experiment it seems safe to tentatively reject the null hypothesis that social workers are not influenced by administrative mandate and accept the hypothesis that social workex' clinical judgement is significantly influenced by administrative needs.

\section{CRITIQUE}

It seems appropriate to qualify the support for accepting the hypothesis of this experiment with the term "tentatively" for several reasons. First, there was clearly ambiguity in the perception of the independent variable by the subjects which tended to obscure the meaning of the results. Second, one of the experimental groups was not significantly different in its discharge rate from the control group although it was significantly different from the other experimental group's responses. Third, differences in actual turnover rate between hospitals were not adequately controlled in the experimental design. All three of these observations suggest that there were inadequacies in the experimental design which could be improved upon in order to strengthen the validity of the study.

Anothex variable which tends to confound an experimental design of this type is the use of a questionnalre to serve as the basis for testing and data collection. The questionnalre, no matter how we11 designed, is an artificlal situation and thus can never have exactly 
the same impact as real clinical situations. It becomes a matter of conjecture as to how the subjects would be thinking at any given time during which the test is being administered.

One way of decreasing the ambiguity of the presentation of the Independent variable would be to make the mandate more directly and clearly related to the dependent variable. For example, in testing for differences in discharge rate the administrative need may have been worded "your immediate superior has just instructed you to discharge as many cases as possible because..." This would also alter the potency of the directive by personalizing it. In this case, it might also be useful to ask the subjects for their subjective response to being given this type of directive.

Since actual turnover rate may well be a pertinent variable when discussing discharges, there should be other ways of controlling for this. It would have been appropriate to choose only hospitals with similar turnover rates and types of care available. For example, some VA hospitals may cater to longer term chronic care while others provide specialized surgery or acute care.

Randomization of assignment to the initial groups would be another method of minimizing differences between groups which are not related to the independent variable. If the researcher could be on hand to administer the tests, that would resolve the problem of collaboration between subjects. 
IMPLICATIONS

This study shows that social workers do attend to non-clinical, external needs in forming clinical decisions. This has implications for social work practice. It suggests that to some degree the needs of the Individual are subjugated to the needs of the institution or the pool of patients as a whole. Since the independent variable was presented subtly, yet still seemed to influence the responses, it suggests that the influence of external demands may take place on an unconscious or preconscious level. While this experiment did not test whether the effect was conscious, this variable night be an interesting one to study in the future. It is important that social work practitioners are aware of their priorities and motivations in making decisions. The client depends upon health professionals to be serving his needs. The institution also has needs which may not be consonant with those of the client. Do we as social workers keep ourselves aware of those overt and covert institutional needs? Do we demand to be kept informed as to the motivation and reasoning for the directives we receive? What do we do with conflicts which arise between what we believe is in the best interest of the client and what we are feeling compelied to do by our administrative superiors?

As mentioned earlier in this paper, social workers are increasingly held responsible for their individual practice. The more we are recognized as professionals, the more emphasis there is for accountability. We are advised to carry malpractice insurance, and to be aware of the responsibility we carry as professional health care 
practitioners, but are we allowed to exercise our best clinical judgement in our practice? Equally important is the question, do we allow. ourselves to be manipulated into making decisions which do not refiect our best clinical judgement.

Future research in this area might test the effect of varying degrees of strength in the presentation of the independent variable. The researcher wonders whether a negative reaction might occur, a resistance to operationalize on the part of the line worker when given increasingly stronger adminjstrative directives related to clinical material. One might also look at the effect of varying degrees of information presented in regard to the directive, i.e. justification which the social worker can relate to, or the extent to which the worker believes that he can participate in the decisions made. This information might address the question, what type of communication:and amount of communication between clinical workers and the administrative representatives would best meet the needs of both the client and the institution and also have the optimum chance of being operationalized. Finally, the study of the impact of administrative needs on clinical decision making need not be limited to social work as a profession. Other professional groups such as psychologists, physicians and nurses are subjected to simflar pressures and external influences in exercising clinical judgement. Further research might also include these professions either individually or in comparison to each other in regard to their response to administrative needs. 


\section{A SELECTED BIBLIOGRAPHY}

Austin, M.J. and Kosberg, J.I. 1976. "Nursing Home Decision Makers and the Social Service Needs of Residents," Social Work in Health Care, 1(4), 447-55.

Barber, G.M. 1973. "A Sociological Analysis of Labeling Overutilization in a Municiple Teaching Hospital," unpublished PhD thesis, Florence Heller Graduate School for Advanced Studies in Social Welfare, Brandeis University in Krel1, G. 1977. "Overstay Among Hospital Patients: Problems and Approaches," Health and Social Work, 2(1), 163-178.

Beige1, A. . 1975. "The Psychiatrist-Administrator: Odd Man Out?" Community Mental Health Journal, 2(2), 129-135.

Blackwel1, B.L. 1977. "The Principles and Problems of Evaluation," Community Mental Health Journal, 13(2), 175-87.

Brehmer, B.: 1973. "Note on Clinical Judgement and the Formal Characteristics of Clinical Tasks," Umea Psychological Reports, 77.

Cohen, M.W. 1976. "Citizen Participation in the Decision-Making Activities of Formal Social Service Agencies: An Unreasonable Goal?" Community Mental Health Journal, 12(4), 355-64.

Davis, A.J. 1976. "Role, Function and Decision Making in Community Mental Health," Nursing Research, 25 (4), 256-8.

Estes, R.J. 1975. "Learning Style Preferences of Community Mental Health Professionals," Community Mental Health Journal, 11(4), 450-65.

Goldberg, L.R. 1959. "The Effectiveness of Clinicians' Judgements: The Diagnosis of Organic Brain Damage from the Gender Gestalt Test," Journal of Consulting Psychology, 23, 25-33.

Hayles, L.S. 1975. "Administrative Considerations in Developing a Volunteer Program," Hospital Community Psychiatry, 26(3), 143-5.

Hinsch, S.; Schulman, L.C. 1976. "Participatory Governance: A Model for Shared Decision Making," Soclal Work in Health Care, 1(4),

Holt, R.R. 1958. "Clinical and Statistical Prediction: A Reformulation and Some New Data," Journal of Abnormal and Social Psychology, $56,1-12$. 
Howe11, J.P. 1976. "The Characteristics of Administrators and the Effectiveness of Community Mental Health Centers," Administration in Mental Health, 3(2), 125-32.

Howe11, J.P. 1977. "The Characteristics of Administrators and the Effectiveness of Community Mental Health Centers," (letter) Administration in Mental Health, 4(2), 99-101.

Hungate, J.I., Jr. 1964. "A Guide for Training Local Public Welfare Administrators" in Hirsch, S.; Schulman, L.C. 1976 "A Model for Shared Decision Making," Social Work in Health Care, 1(4), 433-46.

Hunt, W.A.; Arnhoff, F.N. and Cotton, J.W. 1954. "Rellability, Chance and Fantasy in Interjudge agreement Among Clinicians," Journal of Clinical Psychology, 10, 292-96.

Iacono, C.U. 1976. "Judgmental and Statistical Prediction: A Coalition," Dissertation Abstracts International, 36 (10-B), 5231.

Kre11, G. 1977. "Overstay Among Hospital Patients: Problems and Approaches," Health and Social Work, 2(1), 163-78.

Kupst, M.J.; Reidda, P.; McGee, T.F. 1975. "Community Mental Health Boards: A Comparison of Their Development, Functions, and Powers by Board Members and Mental Health Center Staff," Community Mental Health Journal, $11(3), 249-56$.

Lawrence, L.C.; Smith, P.C. 1955. "Group Decision and Employee Participation," Journal of Applied Psychology, 39, 334-7.

Little, K.B. 1967. "Research Etiquette in the Clinician's Behavior," Journal of Consulting Psychology, 31, 16-18.

Meeh1, P.E. 1960. "The Cognitive Activity of the Clinician," American Psychologist, 15, 19-27.

Nash, K.B.; Mittlefehldt, V.A. 1975. "Supervision and the Emerging Professional," American Journal of Ortho Psychiatry, 45 (1) 93-101.

O'Neil1, F.J. 1970. "On Administrative Psychiatry," Psychiatric Quarterly, 44, 359-65.

Perez, F.I. 1976. "Behavioral Analysis of C1inical Judgment," Perceptual and Motor Skills, 43(3), 711-8.

Siegel, S. 1956. Nonparametric Statistics, New York, McGraw Hill Book Company.

Signell, K.A. 1975. "Following the Blackfoot Indians: Toward Democratic Administration of a Community Mental Health Center," Community Mental Health Journal, 11(4), 430-49. 
Soethe, J.W. 1974. "An Analysis of Judgements Made by Four Groups of Professional Educators and Their Student Counterparts," Dissertation Abstracts International, 34 (7A), 4009.

Soskin, W.F. 1959. "Influence of Four Types of Data on Diagnostic Conceptualization in Psychological Testing," Journal of Abnormal and Soctal Psychology, 58, 69-78.

Spencer, D.A. 1977. "The Discharge of Mentally Handicapped Patients to Residential Care," British Journal of Psychiatry, 130, 127-30.

Tuecker, H.B. 1971. Social Work Administration: Principles and Practice, New York, Association Press.

Wattenberg, S.H. 1977. "Comparison of Opinions of Social Work Administrators Toward Leadership Tasks," Social Work in Health Care, $2(3), 285-93$.

Weinberg, G.H. and Schumaker, J.A. 1974. Statistics: An Intuitive Approach, Monterey, CA, Brooks/Cole Publishing Company. 
APPENDICES 


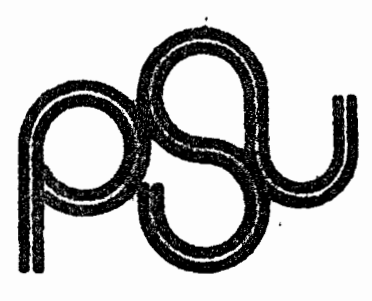

March 15, 1979

MEMORANDU M

PUIILLAND UNIVE:RSITY p. $0.60 \times 751$ rlland ore!joul $9720 ?$

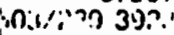

college ol sor.sil raeni.r. iseliatiment ad In:yenolixdy

TO: Richard Anderson

School of Social Work

FROM: Ronald E. Smlth, Cha1rman

Human Subjects Research Review Committee

In accordance with your request, the Human Subjects Research Review Commlttee has reviewed your proposal ent1tled, "The Effect of Administrative Mandate on Social Workers' Clinical Decision Making"

for compliance with DHEW policles and regulations on the protection of human subjects.

The comittee is satisfled that your provisions for protecting the rights and welfare of all subjects particlpating in the research are adequate and therefore the project 18 approved. Any conditions relative to this approval are noted below.

Conditions: None

RES : ev

cc: Offlce of Graduate Studies and Research

Bernard Ross

James Breedlove

Guido Pinamonti

Ronald E. Smith 
RESEARCH PROPOSAL FOR VA HOSPITAL RESEARCH COMMITTEES

PROJECT TITLE

The effect of administrative mandate on social workers' clinical decision making.

INVESTIGATOR

Richard Anderson

\section{PURPOSE}

To determine the extent to which social workers' clinical judgment is altered by administrative needs.

PLAN OF APPROACH

a. In the course of duty, hospital social workers are often called upon to make crucial clinical decisions. These decisions may be made autonomously or they may be made as a participating member of a team or in conjunction with other professionals. In any case, these decisions affect the treatment and outcome of the clients' situation and ultimately their welfare.

Two examples of the types of decisions social workers must make are:

1. Is the patient ready for discharge or should he be retained for further inpatient treatment; and

2. does this client require outpatient services or can he sustain his positive adjustment to the community without further services.

Ideally, one might regard such clinical decisions and the notion of a professional's clinical judgment as sacred and thus incorruptible. In practice, there are numerous intervening reality factors which might influence the outcome of the decision. A few of these factors are: priority of sc over NSC veteran's needs, availability of hospital beds or community services, funds available for extended treatment, trends in health care, and administrative census requirements which prove crucial to future budgetary considerations.

Taking only the last factor, which will be designated "Administrative Needs," this project will explore its relationship and effect upon Social Workers' clinical judgment. 
b. Initially the researcher will construct 10 short case histories each of which will contain the same categories and amounts of information. All cases will be male and they will be veterans who are currently residing in a V.A. Hospital. These histories will be presented to a group of MSW level medical. socilal workers who will be asked to make two decisions regarding each case--first, should the patient be discharged or retained as an inpatient, and second, the social workers will be asked to rate the degree of certainty of their decisions on a 5 point scale. This then would result in 30 responses from each worker. This will serve as a pretest to select the 5 case histories which best represent a continuum of responses.

These five case histories will then be presented to all MSW level social workers in 3 separate V.A. hospitals. These staffs will serve as Groups A, B, and C. Group A w111 be designated as experimental. In addition to being asked to make a decision regarding discharge and indicating certainty of that decision based on the 5 case presentations there will be one extra item of information for the workers to process. Group A will be told that "the hospital administration hopes to reduce the number of beds used in the hospital."

Group B will also be designated as experimental. They will make the same 10 decisions as Group A based on the same 5 case histories but they will be given an opposite administrative need to consider. Group B will be told that "the hospital administration hopes to encourage full occupancy of beds."

Group C will serve as a control. They will be asked to make the same decisions as Groups A and B based on the same case histories but they will not be given an "administrative need" to consider.

All members of each of the three groups will be asked to fill out a preliminary form indicating their sex, age, rank in the organization, number of years of post MSW experience, and number of years of V.A. service in social work. The case presentations and "administrative needs" information will be provided on a printed form with written instructions for completion in order to assure uniformity. All subjects will be blind with respect to the purpose and hypothesis of this experiment. All data will be returned to the investigator for analysis.

\section{METHOD OF INVESTIGATION}

a. Techniques to be used: Written questionnaires directed to professional social workers as subjects will be used to gather all data.

b. Population size: Total $N=44$. Individual hospital social work staffs equal 9,13 and 22 respectively.

c. Method of evaluation: Data will be analyzed statistically for significant differences between groups and for correlation of responses according to demographic and work experience variables. 
d. Duration of investigation: It is planned that written materials will be distributed this autumn to subjects and returned to the investigator for data analysis by December 1978. It is expected that results and conclusion will be reported by March 1979 .

e. Human use statement: The subjects used in this study will be V.A. social workers. In no instance will they be identified by name. Rather a code will be used for identifying the questionnaires. All data will be kept protected under lock and key and will not be available to anyone other than the investigator and his advisor. It will be destroyed after the conclusion of the study. No one will be required to participate except on a voluntary basis. Once the paper has been completed the nature of the study and its complete contents will be available to all of the participants for review and comments. If the groups so desire, the investigator will present the material at a discussion meeting.

\section{INVESTIGATOR'S BACKGROUND:}

Research Assistant for two studies which resulted in publication, "Evaluation of Lithium Therapy in Chronic Alcoholism"--Clinical Medicine, and Electrocardiographic changes during Lithium Therapy--Journal of the Maine Medical Association.

B.A. Psychology - University of Delaware, 1972

Current MSW candidate, P.S.U., Portland, Oregon

\section{SUPPLEMENTAL INFORMATION:}

There are no budget requests. Costs will be assumed by the investigator. This research study will serve to fulfill the investigator's practicum-thesis requirements for the Master's degree. It has approval of the School of Social Work at Portland State University. I will have a faculty research advisor as consultant to this project. 
FINAI QUESTIONNAIRE

Instructions: Read Carefully and Fully

You will be presented with five brief case histories of male veterans who are currently inpatients in a fictitious V.A. Hospital. Please respond to this material based on your general professional experience rather than responding only from the context of your present work setting. In each of the cases you should decide first whether the client should be discharged from the hospital or retained for further treatment and secondly indicate the degree of certainty in your decision. It is given that the hospital administration hopes to reduce the number of beds used in this hospital.

It is imperative that you do not discuss your reactions or responses to this test with anyone else until all data has been collected as this would tend to bias the results. All responses will be confidential and identified by number only.

I would appreciate receiving any criticism or comments you may have in regard to this questionnaire and $I$ will be glad to share my results and conclusions with you at a later date. Thank you for your cooperation.

Initially, please fill in the following five items of personal variables:

1. Sex: (Circle one) Male Female

2. Age:

3. Rank in the service: (Circle one)

S. Worker GS 9 S. Worker GS 11 Supervisor Chief

4. Number of years of post MSW experience

5. Number of years of V.A. service in social work 
FINAL QUESTIONNAIRE

\section{Instructions: Read Carefully and Fully}

You w11l be presented with five brief case historles of male veterans who are currently inpatients in a flctitlous V.A. Hospltal. Please respond to this material based on your general professional experience rather than responding only from the context of your present work setting. In each of the cases you should decide first for further treatment and secondly indlcate the degree of certainty in your decision. It is given that the hospital administration hopes to Increase the number of beds used in this hospltal.

It is imperative that you do not discuss your reactions or responses to this test with anyone else until all data has been collected as this would tend to blas the results. All responses will be confidential and ldentified by number only.

I would appreclate receiving any criticism or comments you may have in regard to this questionnalre and I will be glad to share my results and conclusions with you at a later date. Thank you for your cooperation.

Initially, please f1ll in the following five Items of personal varlables:

1. Sex: (Clrcle one) Male Female

2. Age:

3. Rank in the service: (Circle one)
S. Worker GS 9
S. Worker GS 11
Supervisor
Chlef

4. Number of years of post MSW experfence

5. Number of years of V.A. service In soclal work 


\section{FINAL QUESTIONNAIRE}

\section{Instructions: Read Carefully and Fully}

You will be presented with five brief case histories of male veterans who are currently inpatients in a fictitious V.A. Hospital. Please respond to this material based on your general professional experience rather than responding only from the context of your present work setting. In each of the cases you should decide first whether the client should be discharged from the hospital or retained fur further treatment and secondly indicate the degree of certainty in your decision.

It is imperative that you do not discuss your reactions or responses to this test with anyone else until all data has been collected as this would tend to bias the results. All responses will be confidential and identified by number only.

I would appreciate receiving any criticism or comments you may have in regard to this questionnaire and $I$ will be glad to share my results and conclusions with you at a later date. Thank you for your cooperation.

Initially, please fill in the following five items of personal variables:

1. Sex: (Circle one) Male Female

2. Age:

3. Rank in the service: (Circle one)
S. Worker GS 9
S. Worker GS 11
Supervisor
Chief

4. Number of years of post MSW experience:

5. Number of years of V.A. service in social work: 


\section{Case 非 1}

This 72-year-old veteran has been an inpatient in a chronic psychiatric ward for the last five years. His major diagnosis is schizophrenia, chronic, undifferentiated. The veteran is single with no known family. A guardian handles his funds as he is judged incompetent. Financial resources include VA benefits as well as a small S.S. check. He has been hospitalized for the major part of his life and has adjusted well to the hospital routine. The nursing staff considers him to be "an ideal patient." He is ambivalent about leaving the hospital for any other setting.

A. The client should be: (circle one)
1. discharged
2. retained as inpatient

B. What is the degree of certainty in your decision? (circle one)
1. Very unsure
2. Somewhat unsure
3. Unsure/sure 4. Somewhat sure
5. Very sure

\section{Case 非}

This 41-year-old veteran was admitted to this VA hospital two weeks ago with a diagnosis of schizophrenia, paranoid type, acute onset. He has been experiencing hallucinations both visual and auditory and believes that he is "wired up" to the CIA. He is separated from his wife who supports their two children. Presently he has no income and has been living from limited savings in an apartment over the past three months. He has no previous admissions. His ability to care for himself has steadily deteriorated over the past three months. He is cooperative on the ward but is often confused and disoriented. He has a brother in the immediate area who seems to be concerned and interested.

A. The client should be: (circle one)
1. discharged
2. retained as an inpatient

B. What is the degree of certainty in your decision? (circle one)

1.Very unsure 2.Somewhat unsure 3. Unsure/sure 4. Somewhat sure 5.Very sure 
This single 19-year-old veteran was admitted to this VA hospital ten days ago due to drug addiction. He has been heavily into the drug culture for several years, has never held steady employment and has no particular job skills. While he has been detoxified and is both lucid and oriented, he shows little insight to his problems. He has spent most of his time trying to manipulate the staff and making excessive demands. He has two previous drug-related admissions. His family is located several states away and has no interest in the veteran. While undernourished, he is in good physical condition.

A. The client should be: (circle one)

1. 2. retained as inpatient

B. What is the degree of certainty in your decision? (Circle one)

1.Very unsure 2.Somewhat unsure 3. Unsure/sure 4. Somewhat sure 5.Very sure

Case 非 4

This 35-year-old veteran has been a patient on an acute psychiatric ward in this VA hospital for the past month. His diagnosis is passiveaggressive personality. He has functioned only marginally in employment situations, frequently getting into arguments and his wife does not want him back home because he is "irresponsible" and has been physically assaultive. On the ward he presents himself as a cooperative, conscientious patient but avoids confrontation and has had a few explosive episodes. He wants to return to his wife and home but denies that there are any real problems with his marriage. He has had two previous admissions related to short term alcohol detoxification.

A. The client should be: (Circle one)
1. discharged
2. retained as inpatient

B. What is the degree of certainty in your decision? (Circle one)

1.Very unsure 2. Somewhat unsure 3 .Unsure/sure 4. Somewhat sure 5 .Very sure 
This 56-year-old veteran has been a patient in this VA hospital for two years. His primary diagnosis is manic depressive, manic type. He was recently divorced by his wife who is caring for their three chlldren. He had two previous admisstons within the last five years during manic episodes and returned home after them. Since his readmission this last time he has not completely stabilized on medication. From time to time he becomes overactive, overtalkative, loses his judgment and wanders through the night. He receives VA benefits and S.S. disability.

A. The client should be: (Circle one)
1. discharged
2. retained as inpatient

B. What is the degree of certainty in your decision? (Circle one)

1.Very unsure 2.Somewhat unsure 3. Unsure/sure 4. Somewhat sure 5.Very sure 